\title{
Dietary Mercury Exposure Resulted in Behavioral Differences in Mice Contaminated with Fish-Associated Methylmercury Compared to Methylmercury Chloride Added to Diet
}

\author{
Jean-Paul Bourdineaud, ${ }^{1}$ Masumi Marumoto, ${ }^{2}$ Akira Yasutake, ${ }^{2}$ and Masatake Fujimura ${ }^{2}$ \\ ${ }^{1}$ Bordeaux University-CNRS, UMR EPOC 5805, Arcachon Marine Station, place du Docteur Peyneau, \\ 33120 Arcachon, France \\ ${ }^{2}$ Pathology Section, Department of Basic Medical Sciences, National Institute for Minamata Disease, \\ 4058-18 Hama, Minamata, Kumamoto 867-0008, Japan \\ Correspondence should be addressed to Masatake Fujimura, fujimura@nimd.go.jp
}

Received 16 April 2012; Revised 12 June 2012; Accepted 19 June 2012

Academic Editor: João B.T. Rocha

Copyright () 2012 Jean-Paul Bourdineaud et al. This is an open access article distributed under the Creative Commons Attribution License, which permits unrestricted use, distribution, and reproduction in any medium, provided the original work is properly cited.

Methylmercury (MeHg) is a potent neurotoxin, and humans are mainly exposed to this pollutant through fish consumption. However, in classical toxicological studies, pure methylmercury chloride $(\mathrm{MeHgCl})$ is injected, given to drink or incorporated within feed assuming that its effects are identical to those of $\mathrm{MeHg}$ naturally associated to fish. In the present study, we wanted to address the question whether a diet containing $\mathrm{MeHg}$ associated to fish could result in observable adverse effects in mice as compared to a diet containing the same concentration of $\mathrm{MeHg}$ added pure to the diet and whether beneficial nutriments from fish were able to counterbalance the deleterious effects of fish-associated mercury, if any. After two months of feeding, the fishcontaining diet resulted in significant observable effects as compared to the control and MeHg-containing diets, encompassing altered behavioral performances as monitored in a Y-shaped maze and an open field, and an increased dopamine metabolic turnover in hippocampus, despite the fact that the fish-containing diet was enriched in polyunsaturated fatty acids and selenium compared to the fish-devoid diets.

\section{Introduction}

Methylmercury chloride ( $\mathrm{MeHgCl})$, the most toxic form of mercury, is a potent neurotoxin, to which human beings are mainly exposed through fish consumption. In classical toxicological studies, $\mathrm{MeHg}$ is most often injected intraperitoneally, instilled in the trachea, or dissolved in drinking water, which are not the natural routes for $\mathrm{MeHg}$ entrance into the body. In other cases $\mathrm{MeHgCl}$ is added to the diet. On the other hand, we have in a recent past exposed mice to diets containing fish and mimicking the Wayana Amerindians mercurial contamination or the Western populations' average fish consumption $[1,2]$. A more classical approach consisting in dispersing a given quantity of methylmercury $(\mathrm{MeHg})$ within diet preparations had been precluded because our working postulate is that the supramolecular form under which $\mathrm{MeHg}$ enters the body is of crucial importance, contrarily to the common assumption according to which the toxicological outcome of $\mathrm{MeHg}$ incorporated into fish tissue is identical to that from $\mathrm{MeHgCl}$ added to the same matrix. In this context, a higher faecal excretion and lower tissue accumulation, as well as metallothionein induction in rats following exposure to methylmercury naturally incorporated in fish compared to methylmercury chloride added to the same matrix, have been reported [3]. Moreover, the chemical form of methylmercury in fish has been identified as methylmercury-cysteine (MeHg-cysteine), probably as part of larger peptides [4]. Therefore, one can suspect a different trophic transfer rate through the intestinal barrier and a different early toxicity for ingested free and 
protein-bound methylmercury. It has well been established that MeHg-cysteine was not hydrolyzed by gastric acidic juice and remained intact [4]. The acute toxicity of solubilized $\mathrm{MeHg}$-cysteine has been reported to be considerably lower than $\mathrm{MeHgCl}$ both in vivo [5] and in vitro [6]. In addition, many compounds within fish flesh or brought by diet are likely to influence the trophic transfer rate and the toxicity outcomes of $\mathrm{MeHgCl}$. For instance, selenium and vitamin $\mathrm{E}$ are decreasing the overall toxicity of $\mathrm{MeHgCl}[7,8]$, whereas fruit or tea consumption decreases mercury accumulation within body for the same number of eaten fish meals $[9,10]$. The precise quality of dietary fats also modulates the $\mathrm{MeHg}$ toxicity and the steroidogenesis in rats $[11,12]$.

Therefore, the aim of the present work was to address the questions of whether a diet containing "naturally" accumulated $\mathrm{MeHg}$ in fish flesh could result in differential biological outcomes as compared to $\mathrm{MeHgCl}$ added pure to diet. After two months of feeding with such diets, we analyzed the mercury accumulation in tissues, the mice body growth kinetics, the possible behavioral impairments, and the concentration of neurotransmitters in various brain structures.

\section{Materials and Methods}

2.1. Preparation of the Mice Diets. The H. aimara fish whose flesh was used was caught in French Guiana in the Sinnamary River, known to be contaminated by methylmercury mostly originating from the Petit-Saut hydroelectric reservoir [13]. The dry flesh of this animal contained $5 \mu \mathrm{g} \mathrm{Hg} / \mathrm{g}$. The $H$. aimara fish were thawed, minced, and lyophilized. Then the fish powder was ground in a kitchen blender. The nutrient composition and the metal content of the $H$. aimara fish powder have already been described [1]. The special diets were manufactured by Special Diets Services (Witham, Essex, United Kingdom; French commercial representation: Dietex, Saint-Gratien, France). The control diet was vegetarian (Rat and Mouse no. 1 maintenance diet, abbreviated to RM1 diet, Special Diets Services). The $H$. aimara fish-containing diet was prepared by adding $4.88 \%$ of lyophilized fish powder to the diet ingredients. The methylmercury chloride-containing diet was prepared by adding $1 \mathrm{~L}$ of a $1.5 \mathrm{mg} / \mathrm{L}$ solution of $\mathrm{MeHg}$ in a blend of ingredients allowing the preparation of $6 \mathrm{~kg}$ of diet. The nutrient compositions of the control RM1 and the two prepared regimens are given in Table 1 (the analyses were carried out by Special Diets Services). A comparison of the diets' compositions showed some minor differences between the control and the $\mathrm{MeHg}$ diets on one side, and the fish diet on the other side. Apart from the content in mercury, the control and $\mathrm{MeHg}$ diets are identical. The fish diet contained $3.7 \%$ more protein than the control and $\mathrm{MeHg}$ diets (18.1\% compared to $14.4 \%$ ). It also contained more of some polyunsaturated fatty acids (PUFA): 290, 70, 40, and 150 ppm of docosahexaenoic, docosapentaenoic, erucic, and eicosapentaenoic acids against $<20,<20,20$, and $<20$ ppm for control and $\mathrm{MeHg}$ diets. We quantified the total mercury content of the two prepared regimens and found $253 \pm 38$ and $237 \pm 23 \mathrm{ng} \mathrm{Hg} / \mathrm{g}$ of food pellets for the $\mathrm{MeHg}$ and fish diets, respectively.
TABLE 1: The composition of the diets used ${ }^{\mathrm{a}}$.

\begin{tabular}{|c|c|c|}
\hline & $\begin{array}{l}\text { Control and } \\
\text { MeHg diets }\end{array}$ & Fish $\operatorname{diet}^{\mathrm{b}}$ \\
\hline Moisture & 10 & 10 \\
\hline Fat & 2.71 & 2.66 \\
\hline Protein & 14.38 & 18.08 \\
\hline Fibre & 4.65 & 4.45 \\
\hline Ash & 6.00 & 5.94 \\
\hline \multicolumn{3}{|l|}{ Carbohydrates } \\
\hline Starch & 45.0 & 43.3 \\
\hline Sugar & 4.05 & 3.85 \\
\hline Pectin & 1.52 & 1.45 \\
\hline Hemicellulose & 10.17 & 9.67 \\
\hline Cellulose & 4.32 & 4.11 \\
\hline Lignin & 1.68 & 1.60 \\
\hline \multicolumn{3}{|l|}{ Fatty acids } \\
\hline \multicolumn{3}{|l|}{ Saturated fatty acids } \\
\hline C12:0 lauric & 0.02 & 0.02 \\
\hline C14:0 myristic & 0.14 & 0.14 \\
\hline C16:0 palmitic & 0.31 & 0.31 \\
\hline C18:0 stearic & 0.04 & 0.04 \\
\hline \multicolumn{3}{|l|}{ Monounsaturated fatty acids } \\
\hline C14:1 ( $\omega 5)$ myristoleic & 0.02 & 0.02 \\
\hline C16:1 $(\omega 7)$ palmitoleic & 0.09 & 0.09 \\
\hline C18:1 ( $\omega 9)$ oleic & 0.77 & 0.74 \\
\hline \multicolumn{3}{|l|}{ Polyunsaturated fatty acids } \\
\hline C18:2 ( $\omega 6)$ linoleic & 0.69 & 0.66 \\
\hline C18:3 ( $\omega 3)$ linolenic & 0.06 & 0.05 \\
\hline C20:4 ( $\omega 6)$ Arachidonic & 0.13 & 0.13 \\
\hline $\begin{array}{l}\text { C20:5 }(\omega 3)(\text { EPA }) \\
\text { Eicosapentaenoic }\end{array}$ & $<0.002$ & 0.015 \\
\hline C22:1 ( $\omega 9)$ erucic & 0.002 & 0.004 \\
\hline $\begin{array}{c}\text { C22:5 }(\omega 3)(\mathrm{DPA}) \\
\text { Docosapentaenoic }\end{array}$ & $<0.002$ & 0.007 \\
\hline $\begin{array}{c}\text { C22:6 }(\omega 3)(\text { DHA }) \\
\text { Docosahexaenoic }\end{array}$ & $<0.002$ & 0.029 \\
\hline
\end{tabular}

${ }^{a}$ Nutrients and compounds are given as their percentages in the diets.

${ }^{\mathrm{b}}$ Fish diet : mice were fed a $4.9 \%$ aimara flesh-containing diet.

The control RM1 diet contained $7.8 \pm 1.9 \mathrm{ng} \mathrm{Hg} / \mathrm{g}$ of food pellets. The content of several other metals in the control, $\mathrm{MeHg}$ and fish-containing regimens was assessed (Table 2). Metals were assayed by ICP-MS (Antellis, Toulouse, France). The diets metal levels were below the detection threshold for $\mathrm{Ag}(<0.02 \mathrm{mg} / \mathrm{kg})$, As $(<0.1 \mathrm{mg} / \mathrm{kg})$, Au $(<0.05 \mathrm{mg} / \mathrm{kg})$, Bi $(<0.02 \mathrm{mg} / \mathrm{kg}), \quad \mathrm{Sb}(<0.5 \mathrm{mg} / \mathrm{kg}), \quad S n \quad(<0.5 \mathrm{mg} / \mathrm{kg}), \mathrm{Tl}$ $(<0.05 \mathrm{mg} / \mathrm{kg})$, and $\mathrm{V}(<0.5 \mathrm{mg} / \mathrm{kg})$. The $\mathrm{MeHg}$ and fish diets contained equal amounts of mercury whereas the control diet was 30-times poorer in this metal. The fish diet was richer in selenium than the control and $\mathrm{MeHg}$ diets ( $0.48 \mathrm{ppm}$ against 0.30 ), and apart from mercury and selenium, the 3 diets were comparable. 
TABLE 2: The metal and selenium composition of the diets used ${ }^{\mathrm{a}}$.

\begin{tabular}{lccc}
\hline Element & \multicolumn{3}{c}{ Diets } \\
& Control diet & $\mathrm{MeHg}^{\mathrm{b}}$ & Fish $^{\mathrm{c}}$ \\
\hline $\mathrm{Al}$ & 41.1 & 41.1 & 39.1 \\
$\mathrm{Cd}$ & $64.10^{-3}$ & $64.10^{-3}$ & $62.10^{-3}$ \\
$\mathrm{Co}$ & 0.80 & 0.80 & 0.76 \\
$\mathrm{Cr}$ & 0.72 & 0.72 & 0.69 \\
$\mathrm{Cu}$ & 7.99 & 7.99 & 7.63 \\
$\mathrm{Hg}$ (total) & $\mathbf{8 . 1 0 ^ { - 3 }}$ & $\mathbf{2 5 3 . 1 0 ^ { - 3 }}$ & $\mathbf{2 3 7 . 1 0 ^ { - 3 }}$ \\
$\mathrm{Ni}$ & 0.39 & 0.39 & 0.38 \\
$\mathrm{~Pb}$ & 0.165 & 0.165 & 0.161 \\
$\mathrm{Se}$ & $\mathbf{0 . 3 0}$ & $\mathbf{0 . 3 0}$ & $\mathbf{0 . 4 8}$ \\
$\mathrm{Zn}$ & 41.1 & 41.1 & 40.0
\end{tabular}

${ }^{a}$ Metals and selenium are given in $\mathrm{mg} / \mathrm{kg}$.

${ }^{\mathrm{b}} \mathrm{MeHg}$ : mice were fed a MeHg-containing diet.

'Fish: mice were fed a $4.9 \%$ aimara flesh-containing diet.

2.2. Mice Treatment and Tissue Sampling. Subjects were naïve male mice of the $\mathrm{C} 57 \mathrm{Bl} / 6$ Jico inbred strain obtained from Japan Clear (Tokyo, Japan) at the age of 3 weeks weighing $10.4 \pm 0.24 \mathrm{~g}$. Young animals were used because they grow quickly and because they are more sensitive to $\mathrm{MeHg}$ than older animals. They were first ink-labeled on the ear skin. They were socially housed in standard conditions: room temperature $\left(23^{\circ} \mathrm{C}\right), 12 / 12$ light cycles, and ad libitum food and water. Experiments were performed in compliance with the European Community Council directive of 24 November 1986 (8616091 EEC). Three groups of 16 mice each (8 of which dedicated for each kinetic time points at 29 and 57 days) were fed for 29 and 57 days as follows: one with the control RM1 diet and the two other groups with the $\mathrm{MeHg}$ and fish diets. Mice from the three groups were weighed twice a week throughout the experiment. At the end of the exposure period, mice were subjected to an open-field maze test, in order to quantify anxiety levels, and to a Yshaped maze test, to assess cognitive ability. Thereafter, mice were anesthetized with Pentothal (50 mg/kg, i.p.), blood was immediately collected by puncturing the vena cava, and the vascular system was washed for traces of blood by perfusion with saline $(0.9 \% \mathrm{NaCl})$. Then, tissues were dissected for mercury quantification (blood, several brain structures, liver, kidney) and neurotransmitters quantification (6 different brain structures).

2.3. Activity Test Using an Open-Field Maze. The anxiety test was assessed using the open-field apparatus after Tanaka et al. [14] with slight modifications. This behavioural test was performed using randomly chosen animals ( 8 mice per group) on days 28 and 56, one day before their sacrifice for tissue sampling. The apparatus consisted of a floor $(50 \times 50 \mathrm{~cm})$ surrounded by a $50 \mathrm{~cm}$ high opaque wall. A CCD camera fixed above the apparatus was connected to a Macintosh computer, and the movement of the mouse was analyzed using Image OF (O'Hara \& Co., Ltd., Tokyo, Japan), a modified NIH Image program (developed at the US National Institutes of Health and available on the Internet at http://rsb.info.nih.gov/nih-image/). In this software, the position of the animal was defined as the position of the gravity center of the animal's image, which was calculated every $0.5 \mathrm{~s}$. The total distance traversed by the gravity center was calculated and converted into centimeters. Also, floor area was divided into 25 squares $(10 \times 10 \mathrm{~cm})$, and the location of the animal was classified either as central (nine areas that did not have direct contact with the walls) or peripheral (remaining sixteen areas). Behavior was monitored for $5 \mathrm{~min}$ after placing one mouse at the center of the floor. Between each trial, floor and walls were cleaned with $70 \%$ alcohol followed by wiping with wet cotton.

2.4. Cognitive Test Using a Y-Shaped Maze. To assess spatial learning and memory, mice were tested in the Y-maze. This behavioural test was performed using randomly chosen animals ( 8 mice per group) on days 27 and 55, two days before their sacrifice for tissue sampling. Each mouse was placed at the end of one arm facing the centre of the maze and allowed to move freely within the maze for a period of $5 \mathrm{~min}$. The arm length was $40 \mathrm{~cm}$, the arm width, $10 \mathrm{~cm}$, and the arm height, $35 \mathrm{~cm}$. The total number of arms entered by the mouse and the order of arm entries were recorded. The total number of arms entered provides an indication of locomotor activity, and the order of arm entries provides a measure of spontaneous alternation behaviour [15]. Success in this test is indicated by a high rate of alternation in the control group, indicating that the animals can remember which arm was entered last.

2.5. Mercury Quantification. Animals were chosen randomly for mercury analysis (at day 57, 8 for blood, 6 for liver and kidney, and 3 for each brain structure). Samples were analyzed for total mercury at the National Institute for Minamata Disease (NIMD), Japan, using reliable and sensitive techniques following described procedures [16]. Tissue samples were homogenized $(10 \%, \mathrm{w} / \mathrm{v})$ in distilled water using a Polytron homogenizer (Kinematica GmbH, Littau, Switzerland). Blood was collected from the femoral vein into heparinised tubes. A portion of blood was haemolysed by distilled water $(1: 50)$. Total $\mathrm{Hg}$ levels in the homogenates $(100 \mu \mathrm{L})$ and haemolysed blood $(100 \mu \mathrm{L})$ were determined by an oxygen-combustion gold amalgamation method using an atomic absorption mercury analyzer MD-A (Nippon Instruments Co., Ltd., Osaka, Japan). To control the quality of measurements, a standard reference material from dogfish, DORM2 (National Research Council, Canada) was included in analyses. The certified value of total mercury is $4.64 \pm$ $0.26 \mu \mathrm{g} / \mathrm{g}$ (mean $\pm \mathrm{SEM})$. Our qualification data were $4.51 \pm$ $0.14 \mu \mathrm{g} / \mathrm{g}$ for total mercury (mean $\pm \mathrm{SEM}$ ).

2.6. Neurotransmitters and Associated Metabolites Quantification. The brain homogenates were prepared as follows. Brain regions including the frontal cortex, cortex, hypothalamus, striatum, cerebellum, and midbrain were dissected out from frozen brains. Dissected tissues were frozen immediately in liquid nitrogen and stored at $-80^{\circ} \mathrm{C}$ until use. These tissues were homogenized in $0.2 \mathrm{M}$ perchloric acid (Nacalai Tesque, Kyoto, Japan) containing $100 \mathrm{mM}$ 
EDTA and isoproterenol (ISO) $(100 \mathrm{ng} / \mu \mathrm{L})$ as an internal standard. Homogenates were centrifuged for $15 \mathrm{~min}$ at $0^{\circ} \mathrm{C}$ and $20,000 \mathrm{~g}$. The $\mathrm{pH}$ of each supernatant was adjusted to 3.0 with $1 \mathrm{M}$ sodium acetate and supernatants were then used to determine monoamine levels. Each sample $(10 \mathrm{~mL})$ was injected into an HPLC system (HTEC-500MAD) with electrochemical detection (ECD-300 EICOM, Kyoto, Japan) with an ODS column (EICOMPAC SC-5, $3.0 \mathrm{~mm} \times$ $150 \mathrm{~mm}, \mathrm{EICOM})$. The mobile phase was sodium acetatecitric acetate buffer ( $\mathrm{pH} 3.5$ )/methanol/sodium octane-1sulfonate $(85 \% / 15 \% / 0.21 \mathrm{~g})$, the flow rate was maintained at $0.5 \mathrm{~mL} / \mathrm{min}$, and the temperature of the column was $25^{\circ} \mathrm{C}$. Tissue levels of dopamine (DA), 5-hydroxytryptamine or serotonin (5-HT), and noradrenalin (NE) as well as their metabolites 3,4-dihydroxyphenylacetic acid (DOPAC), 3methoxytryptamine (3-MT) and homovanillic acid (HVA) as DA metabolites, and 5-hydroxyindole-acetic acid (5-HIAA) as a 5 -HT metabolite were measured. Each of the standard solutions for the 6 catecholamines (DA, NE, DOPAC, HVA, 3-MT, and ISO) and 2 indoleamines (5-HT and 5-HIAA) was prepared at a concentration of $0.1 \mathrm{ng} / \mathrm{mL}$. Each standard $(10 \mu \mathrm{L})$ was analyzed by HPLC, and the standard chromatographic peaks per $1 \mathrm{ng}$ for each sample were obtained. The amount of each monoamine was determined with peakarea ratios using an HPLC chromatogram analysis software, eDAQ Power Chrom (eDAQ, NSW, Australia). Values were normalized for the amount of protein in each sample.

2.7. Statistical Analysis. Statistical significance was determined by a one-way ANOVA followed by a Dunnett's multiple comparison test. Data were expressed as the mean \pm SEM. A difference was considered statistically significant when $P<0.05$.

\section{Results and Discussion}

During the timecourse of the present experiment we observed no mortality, and no clinical or histopathological signs of lesions in mice brains whatever the diet given. The mice growth was recorded for two months. It appeared that the weight gain was faster for mice fed the $\mathrm{MeHg}$ and fish diets than the control diet during the first 10 days (Figure 1). At days 3, 7 and 10, the mercury-contaminated mice got body weights 7,4 , and $4 \%$ higher than the control mice, respectively. This effect is easily attributable to the beneficial effects of fish nutriments in the case of the fishcontaining diet but remains hard to explain in the case of the MeHg diet.

3.1. Mercury Quantification. As expected, after 57 days of exposure the mercury concentrations in tissues of both groups of mice dietary contaminated with mercury were much higher than those from mice fed the control diet (Table 3). The mercury concentration increases ranged between 11 and 25 times those recorded in tissues from mice fed the control diet. We could notice a 20 -fold increase in blood mercury for both $\mathrm{MeHg}$ and fish mice compared to control mice. Kidneys were the organs accumulating the highest concentrations of mercury in the organism, reaching

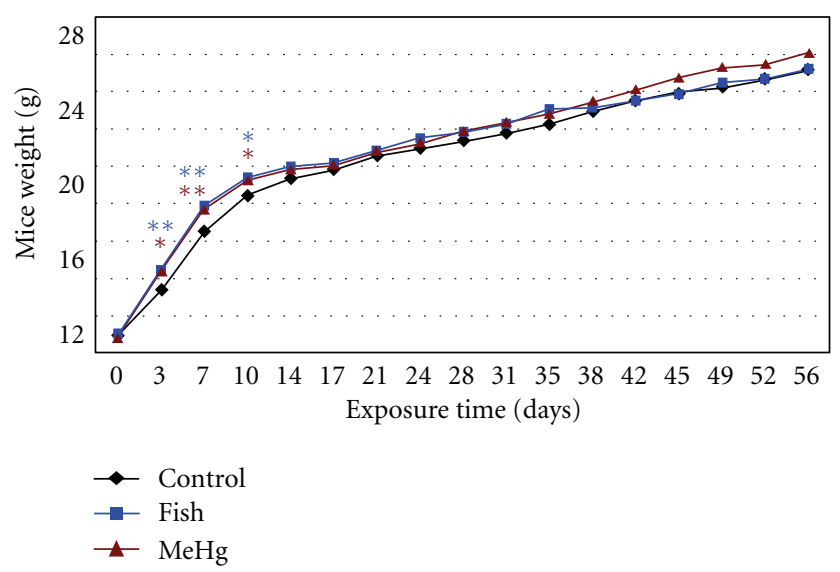

Figure 1: Influence of diet on the body weight growth. Mice were exposed to a control diet ("Control" plot with black diamonds), or a MeHg-containing diet ("MeHg" plot with red triangles), or a fishcontaining diet ("Fish" plot with blue squares). Weights (in grams) were collected at the indicated kinetic time points and the mean weights plotted. Means and standard deviations were calculated from 16 control-, MeHg- and fish-fed mice from the beginning to the 35 th day. From days 38 to 56, they were calculated from 8 animals per diet. The asterisks indicate a significant difference in body weight for mice fed the MeHg- and fish-containing diet compared to those fed the control diet, as determined with a oneway ANOVA followed by a Dunnett's multiple comparison method, ${ }^{*} P<0.05$, and ${ }^{*} P<0.01$.

7.3 and $6.8 \mathrm{mg} \mathrm{Hg} / \mathrm{g}$ in mice fed the $\mathrm{MeHg}$ and fish diets, respectively, a multiplication factor of 17 and 16 compared to the control diet. Worth to note is the heterogeneity of brain structures in terms of mercury accumulation since, for instance frontal cortex accumulated 2.7 and 2 times more mercury than brain stem in mice fed the $\mathrm{MeHg}$ and fish diets, respectively. Except in the striatum, which accumulated 33\% less mercury in animals fed the fish diet compared to those fed the MeHg diet, the mercury concentrations in tissues of mice fed the $\mathrm{MeHg}$ and the fish diets displayed no statistical significant differences, although a trend of smaller concentrations was observed in tissues of mice fed the fish diet. This lower mercury concentration in the striatum of mice fed the fish diet compared to those fed the MeHg diet cannot be explained by a lower blood mercury concentration since we measured the same blood mercury concentrations for both groups of mercury-contaminated mice. This is probably due to the fact that different mercurial chemical species are not transported into tissue cells with the same efficiency by transporters. For instance, the ubiquitous transporters LAT1 and LAT2 efficiently catalyze the uptake of MeHg-L-cysteine but not that of MeHg-D-cysteine or MeHg-glutathione [17]. Furthermore, solubilised MeHg-cysteine is thought to be, at least partly, actively transported via neutral amino acids carrier systems [18-20], while $\mathrm{MeHgCl}$ would be transported via other facilitated processes [20].

In order to mimic the mercury exposure in the Amazon riverside population, rats have been fed with a diet containing $20 \%$ of carnivorous fish caught in the Tapajós River and which flesh contained $1.95 \mu \mathrm{g} \mathrm{MeHg} / \mathrm{g}$, making a mercury concentration in feed of $0.39 \mu \mathrm{g} \mathrm{MeHg} / \mathrm{g}$ [21]. 
TABLE 3: Total mercury concentrations in mice tissues ${ }^{\mathrm{a}}$.

\begin{tabular}{lccc}
\hline Tissues & Control & $\mathrm{MeHg}^{\mathrm{b}}$ & Fish $^{\mathrm{c}}$ \\
\hline Blood $(n=8)$ & $0.010 \pm 0.002$ & $0.21 \pm 0.02$ & $0.20 \pm 0.01$ \\
Brain stem $(n=3)$ & $0.016 \pm 0.006$ & $0.27 \pm 0.07$ & $0.20 \pm 0.07$ \\
Cerebellum $(n=3)$ & $0.016 \pm 0.002$ & $0.33 \pm 0.06$ & $0.26 \pm 0.04$ \\
Frontal cortex $(n=3)$ & $0.031 \pm 0.013$ & $0.73 \pm 0.16$ & $0.41 \pm 0.13$ \\
Hippocampus $(n=3)$ & $0.024 \pm 0.002$ & $0.62 \pm 0.26$ & $0.34 \pm 0.08$ \\
Midbrain $(n=3)$ & $0.020 \pm 0.003$ & $0.41 \pm 0.20$ & $0.23 \pm 0.04$ \\
Striatum $(n=3)$ & $0.018 \pm 0.002$ & $0.49 \pm 0.05$ & $* \mathbf{0 . 3 3} \pm \mathbf{0 . 0 1}$ \\
Liver $(n=6)$ & $0.038 \pm 0.008$ & $0.94 \pm 0.11$ & $0.79 \pm 0.12$ \\
Kidney $(n=6)$ & $0.416 \pm 0.091$ & $7.3 \pm 1.4$ & $6.8 \pm 0.5$ \\
\hline
\end{tabular}

${ }^{\mathrm{a}} \mathrm{In} \mu \mathrm{g} / \mathrm{g}$ for solid tissues or $\mu \mathrm{g} / \mathrm{mL}$ for blood (mean $\pm \mathrm{SD}$ ).

b $\mathrm{MeHg}$ : mice were fed a MeHg-containing diet.

${ }^{\mathrm{c}}$ Fish: mice were fed a $4.9 \%$ aimara flesh-containing diet.

All total mercury concentrations in $\mathrm{MeHg}$ and fish diet samples significantly higher than those in control diet samples, as determined with a one-way ANOVA followed by a Dunnett's multiple comparison method $(P<0.01)$.

The symbol * indicates a significant difference in mercury concentrations for mice fed the fish-containing diet compared to those fed the MeHg-containing diet, as determined with a one-way ANOVA followed by a Dunnett's multiple comparison method. ${ }^{*} P<0.05$. The corresponding value appears in bold characters.

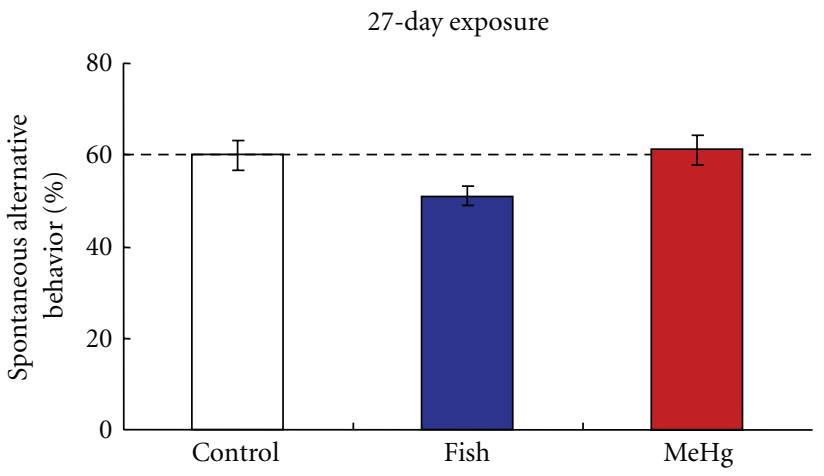

(a)

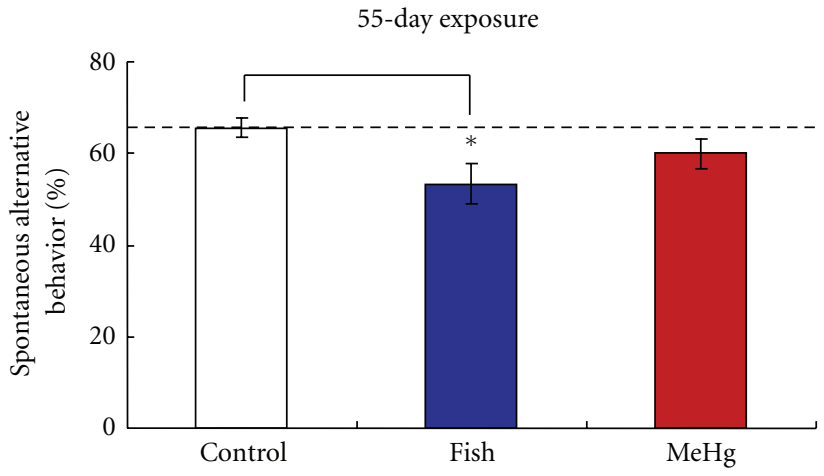

(b)

FIGURE 2: Mice behavior in a Y-shaped maze. Spontaneous alternations were recorded for 5 min ( $\operatorname{mean} \pm \mathrm{SEM}, n=8)$. The asterisk indicates a significant difference between the spontaneous alternations presented in the Y maze by mice fed the fish-containing diet compared to those fed the control diet, as determined with a one-way ANOVA followed by a Dunnett's multiple comparison method, ${ }^{*} P<0.05$, and ${ }^{* *} P<0.01$.

After 84 days of contamination rats presented in their blood cells an increased lipid peroxidation and genotoxicity and an increased systolic blood pressure. Mercury concentrations were $1.31 \mu \mathrm{g} / \mathrm{mL}$ in blood, $0.87,0.89$, and $0.1 \mu \mathrm{g} / \mathrm{g}$ in liver, kidney, and brain, respectively. In the present study, we gave to mice a diet containing $0.24 \mu \mathrm{g} \mathrm{MeHg} / \mathrm{g}$, resulting after 57 days of exposure in mercury concentrations 6.5 and 1.1 times weaker in blood and liver but 8.6 and 4.1 times larger in kidney and brain, meaning that the distribution of methylmercury from blood to tissues is differing between rats and mice.

3.2. Behavioral Modification. The activity of mice was assessed in an open-field maze (Table 4). The quantity of emitted feces, along with the number of rearing events and the number of squares crossed, could not distinguish the three different groups of mice tested after 28 or 56 days of exposure. However, after 56 days of exposure the number of grooming events was significantly decreased for the fish diet mice as compared to the MeHg-fed and control mice, with this decrease reaching 45 and $40 \%$ of the values of the $\mathrm{MeHg}$-fed and control mice, respectively. Additionally, after 56 days of exposure the time spent in center was significantly higher for the fish diet mice as compared to the MeHg-fed and control mice, with this increase representing 2 and 3 -fold the values of the MeHg-fed and control mice, respectively. Anxious mice tend to avoid the center of the open field and to groom more frequently. Therefore, a decrease of grooming events associated to an increase of time spent in the center of the open field indicates an antianxious behaviour.

The Y-maze allowed for the testing of memory function in mice (Figure 2). Spontaneous alternation is a behavioural test dealing with spatial learning and memory. The purpose of the test for the mouse consists in remembering which 
TABLE 4: Mice behavior in an open field maze ${ }^{\mathrm{a}}$.

\begin{tabular}{|c|c|c|c|c|c|c|}
\hline & \multicolumn{2}{|c|}{ Control } & \multicolumn{2}{|c|}{$\mathrm{MeHg}^{\mathrm{b}}$} & \multicolumn{2}{|c|}{ Fish $^{\mathrm{c}}$} \\
\hline & 28th day & 56th day & 28th day & 56th day & 28th day & 56th day \\
\hline Squares crossed & $93 \pm 7$ & $86 \pm 4$ & $86 \pm 6$ & $83 \pm 5$ & $78 \pm 6$ & $84 \pm 5$ \\
\hline Rearing & $23 \pm 2$ & $26 \pm 2$ & $21 \pm 2$ & $28 \pm 3$ & $22 \pm 3$ & $24 \pm 2$ \\
\hline Grooming & $1.7 \pm 0.3$ & $1.25 \pm 0.16$ & $1.5 \pm 0.2$ & $1.38 \pm 0.18$ & $1.9 \pm 0.3$ & ${ }^{\circ, \S} \mathbf{0 . 7 5} \pm \mathbf{0 . 1 6}$ \\
\hline Fecal pellets & $1.4 \pm 0.8$ & $3.8 \pm 1.2$ & $3.7 \pm 1.8$ & $1.7 \pm 0.6$ & $3.9 \pm 1.1$ & $2.3 \pm 0.9$ \\
\hline Time spent in center (s) & $5.3 \pm 1.0$ & $3.6 \pm 0.4$ & $3.8 \pm 0.5$ & $4.7 \pm 1.2$ & $3.7 \pm 0.6$ & ${ }^{\circ, \S} \mathbf{1 0 . 0} \pm \mathbf{1 . 5}$ \\
\hline
\end{tabular}

${ }^{\mathrm{a}}$ Mean $\pm \mathrm{SEM}, n=8$.

${ }^{b} \mathrm{MeHg}$ : mice were fed a MeHg-containing diet.

${ }^{\mathrm{c}}$ Fish: mice were fed a $4.9 \%$ aimara flesh-containing diet.

Values appearing in bold characters highlight those significantly different from the control values.

Circles indicate significant differences in behavioral parameters for mice fed the fish-containing diet compared to those fed the control diet, as determined with the Students test, ${ }^{\circ} \mathrm{P}<0.05$, and ${ }^{\circ} \mathrm{P}<0.01$.

The symbol ${ }^{\S}$ indicates significant differences in behavioral parameters for mice fed the fish-containing diet compared to those fed the MeHg-containing diet, as determined with the Students test, ${ }^{\S} P<0.05$.

maze arm was last visited and trying to enter as many different arms as possible. The task is testing hippocampal memory and can be weakened by lesions to the hippocampus. The sequence of arm entries and total amount of arm entries are scored and a percentage is calculated. The cognition of the animal can be assessed based on the score where a lower score is considered cognitively impaired. After 55 days of exposure, mice fed the fish diet displayed a significant lower rate of spontaneous alternations in the maze compared to MeHg-fed and control mice, strongly suggesting that these animals had difficulties remembering which arm was entered last. After 27 days of exposure, mice fed the fish-containing diet already presented a downward trend concerning the rate of spontaneous alternations but this was statistically nonsignificant.

\section{Neurotransmitters and Associated Metabolites Quantification in Various Brain Structures}

The levels of noradrenalin (NE), dopamine (DA), and 5hydroxytryptamine or serotonin (5-HT) were quantified in various brain structures after two months of feeding with mercury-containing diets. In addition to these three neurotransmitters, the metabolite resulting from the degradation of serotonin, 5-hydroxyindole-acetic acid (5HIAA) and those from the degradation pathway of DA, 3,4-dihydroxyphenylacetic acid (DOPAC), and homovanillic acid (HVA) were also quantified (Table 5).

No differences in levels of neurotransmitters or their metabolites could be observed after one month of exposure in the various brain structures collected. Only after 2 months of exposure could we see differences. The levels of serotonin appeared to be 2 times decreased in brainstem of mice fed the $\mathrm{MeHg}$ diet as compared to those fed the control diet. However, the level of serotonin in the same brain structure from mice fed the fish diet was not significantly different from that of the MeHg-containing diet, and therefore this decrease cannot account for the differences observed in mice behavior. And the same holds true with the 5-HIAA level which was $67 \%$ higher in the striatum of mice fed the fish diet compared to control mice, since the value from the MeHgfed mice was not significantly different. In cerebellum of mice fed the fish diet, the DOPAC level was 2-times higher than that of the control mice. For mice fed the $\mathrm{MeHg}$ diet, the DOPAC level in this brain structure was as high as for mice fed the fish diet, but due to a great variability of values the mean could not be considered significantly different from that of control mice, and therefore the values from both the MeHg and fish diets cannot be taken as different. The dopamine metabolite DOPAC levels were significantly increased in hippocampus and striatum of mice fed the $\mathrm{MeHg}$ diet as compared to those fed the control diet, with increase factors reaching $15-$ and 2.6-fold the values of the control mice, respectively. Accordingly, the dopamine metabolite HVA level was 2.6 times increased in striatum of mice fed the $\mathrm{MeHg}$ diet as compared to those fed the control diet. It has already been described the striatal increase in dopamine and its acidic metabolite DOPAC after exposure of rats to $\mathrm{MeHgCl}$ [22]. However in this latter study the dose of injected $\mathrm{MeHgCl}$ was very high $(0.1-2 \mathrm{mg} / \mathrm{kg} /$ day $)$ compared to the dose used through diet in the present study ( $50 \mu \mathrm{g} / \mathrm{kg} /$ day), suggesting that striatum is more sensitive to methylmercury associated to fish than added pure in the diet. In hippocampus of mice fed the fish diet, the DOPAC level was significantly intermediate between those of mice fed the control and $\mathrm{MeHg}$ diets, since it reached 5 and 0.33 times those of control and $\mathrm{MeHg}$-fed mice, respectively. Additionally, the metabolic turnover was calculated as the ratio of the sum of DOPAC and HVA levels to dopamine to estimate the activity of this metabolic pathway. We calculated a dopamine metabolic turnover of $0.36,0.26$, and 0.52 for mice fed the control, MeHg-containing, and fishcontaining diets, respectively. This indicates that the rate of consumption of dopamine is greater in hippocampus of mice fed the fish-containing diet compared to the other two diets. Previous reports demonstrated that hippocampal dopamine receptors might be necessary for executive function including working memory [23]. The greater dopamine consumption in hippocampus might show the abnormality of hippocampal dopamine receptors. This may explain the decreased 
TABLE 5: Neurotransmitter levels and associated decay products in brain structures of mice fed MeHg- and fish-containing diets.

\begin{tabular}{|c|c|c|c|c|c|c|c|}
\hline \multirow{2}{*}{ Brain structures and diets } & \multirow{2}{*}{ Days } & \multicolumn{6}{|c|}{ Neurotransmitters and decay products $(\mathrm{pg} / \mathrm{mg}$, mean $\pm \mathrm{SEM}, n=3)$} \\
\hline & & $\mathrm{NE}$ & DA & DOPAC & HVA & 5-HT & 5-HIAA \\
\hline \multicolumn{8}{|l|}{ Frontal cortex } \\
\hline \multirow{2}{*}{ Control } & 28 & $10.8 \pm 3.7$ & $2.1 \pm 0.8$ & $1.4 \pm 0.6$ & $3.5 \pm 1.4$ & $4.3 \pm 1.8$ & $8.2 \pm 3.2$ \\
\hline & 56 & $11.1 \pm 3.2$ & $1.8 \pm 0.4$ & $0.25 \pm 0.02$ & $1.4 \pm 0.2$ & $4.4 \pm 2.6$ & $3.6 \pm 0.8$ \\
\hline \multirow{2}{*}{$\mathrm{MeHg}^{\mathrm{a}}$} & 28 & $9.4 \pm 1.5$ & $2.0 \pm 0.6$ & $1.1 \pm 0.5$ & $1.7 \pm 1.0$ & $2.2 \pm 0.6$ & $4.4 \pm 0.6$ \\
\hline & 56 & $5.8 \pm 0.7$ & $1.7 \pm 0.3$ & $0.36 \pm 0.08$ & $0.9 \pm 0.6$ & $0.3 \pm 0.3$ & $2.6 \pm 0.5$ \\
\hline \multirow{2}{*}{ Fish $^{\mathrm{b}}$} & 28 & $16.9 \pm 4.9$ & $2.2 \pm 0.7$ & $0.9 \pm 0.2$ & $3.8 \pm 1.5$ & $5.8 \pm 2.2$ & $6.9 \pm 0.7$ \\
\hline & 56 & $6.8 \pm 3.9$ & $2.0 \pm 0.2$ & $0.7 \pm 0.2$ & $1.1 \pm 0.6$ & $2.1 \pm 1.2$ & $5.7 \pm 2.9$ \\
\hline \multicolumn{8}{|l|}{ Brainstem } \\
\hline \multirow{2}{*}{ Control } & 28 & $15.7 \pm 2.8$ & $7.2 \pm 1.8$ & $1.1 \pm 0.5$ & $2.0 \pm 1.0$ & $4.4 \pm 0.8$ & $21 \pm 7$ \\
\hline & 56 & $12.3 \pm 1.4$ & $3.4 \pm 0.4$ & $0.56 \pm 0.11$ & $0.8 \pm 0.1$ & $4.7 \pm 0.1$ & $10 \pm 1$ \\
\hline \multirow{2}{*}{$\mathrm{MeHg}$} & 28 & $13.2 \pm 0.2$ & $3.6 \pm 0.3$ & $0.73 \pm 0.04$ & $1.04 \pm 0.08$ & $4.1 \pm 0.3$ & $11 \pm 1$ \\
\hline & 56 & $8.4 \pm 4.0$ & $2.3 \pm 0.7$ & $0.68 \pm 0.19$ & $0.73 \pm 0.05$ & $* 2.3 \pm 0.6$ & $8.9 \pm 0.7$ \\
\hline \multirow{2}{*}{ Fish } & 28 & $14.3 \pm 1.7$ & $6.3 \pm 1.5$ & $1.2 \pm 0.6$ & $1.8 \pm 0.8$ & $4.8 \pm 0.6$ & $15 \pm 3$ \\
\hline & 56 & $10.2 \pm 2.2$ & $3.2 \pm 0.8$ & $0.63 \pm 0.15$ & $0.8 \pm 0.1$ & $3.1 \pm 1.0$ & $10 \pm 2$ \\
\hline \multicolumn{8}{|l|}{ Hippocampus } \\
\hline \multirow{2}{*}{ Control } & 28 & $18.5 \pm 4.6$ & $9.4 \pm 3.6$ & $6.6 \pm 5.8$ & $5.4 \pm 3.6$ & $7.1 \pm 2.1$ & $26 \pm 7$ \\
\hline & 56 & $7.9 \pm 1.8$ & $2.4 \pm 0.7$ & $0.17 \pm 0.03$ & $0.7 \pm 0.1$ & $5.0 \pm 1.2$ & $7.6 \pm 1.9$ \\
\hline \multirow{2}{*}{$\mathrm{MeHg}$} & 28 & $13.8 \pm 2.4$ & $4.6 \pm 0.2$ & $2.0 \pm 0.8$ & $3.2 \pm 1.6$ & $5.4 \pm 1.3$ & $12.3 \pm 0.4$ \\
\hline & 56 & $14.4 \pm 10.6$ & $12.8 \pm 0.8$ & $* 2.55 \pm 0.06$ & $0.8 \pm 0.2$ & $12.4 \pm 9.7$ & $49 \pm 3$ \\
\hline \multirow{2}{*}{ Fish } & 28 & $10.5 \pm 2.4$ & $4.2 \pm 0.4$ & $1.0 \pm 0.7$ & $1.8 \pm 0.7$ & $6.1 \pm 1.9$ & $10.1 \pm 1.3$ \\
\hline & 56 & $12.5 \pm 3.3$ & $4.3 \pm 1.2$ & ${ }^{\circ, \S} \mathbf{0 . 8 5} \pm \mathbf{0 . 1 8}$ & $1.4 \pm 0.2$ & $7.5 \pm 2.8$ & $13 \pm 3$ \\
\hline \multicolumn{8}{|l|}{ Striatum } \\
\hline \multirow{2}{*}{ Control } & 28 & $6.0 \pm 1.3$ & $120 \pm 29$ & $68 \pm 15$ & $56 \pm 18$ & $11.6 \pm 4.8$ & $19 \pm 7$ \\
\hline & 56 & $1.3 \pm 0.7$ & $79 \pm 9$ & $31 \pm 5$ & $22.0 \pm 1.4$ & $5.7 \pm 0.1$ & $5.2 \pm 0.3$ \\
\hline \multirow{2}{*}{$\mathrm{MeHg}$} & 28 & $4.6 \pm 1.5$ & $53 \pm 17$ & $60 \pm 21$ & $32 \pm 10$ & $6.5 \pm 1.9$ & $10 \pm 2$ \\
\hline & 56 & $2.8 \pm 0.6$ & $65 \pm 10$ & $* 82 \pm 12$ & $* 43 \pm 5$ & $7.5 \pm 3.3$ & $13.4 \pm 5.1$ \\
\hline \multirow{2}{*}{ Fish } & 28 & $5.2 \pm 1.6$ & $49 \pm 11$ & $23 \pm 8$ & $15 \pm 4$ & $5.0 \pm 1.1$ & $6 \pm 1$ \\
\hline & 56 & $4.9 \pm 1.6$ & $61 \pm 10$ & $54 \pm 14$ & $32 \pm 7$ & $5.0 \pm 1.0$ & ${ }^{\circ} 8.7 \pm 1.0$ \\
\hline \multicolumn{8}{|l|}{ Cerebellum } \\
\hline \multirow{2}{*}{ Control } & 28 & $4.7 \pm 1.4$ & $1.2 \pm 0.4$ & $0.33 \pm 0.11$ & $1.0 \pm 0.5$ & $0.4 \pm 0.1$ & $5.1 \pm 2.4$ \\
\hline & 56 & $9.0 \pm 2.8$ & $1.0 \pm 0.3$ & $0.36 \pm 0.03$ & $0.81 \pm 0.09$ & $2.5 \pm 1.0$ & $3.4 \pm 0.7$ \\
\hline \multirow{2}{*}{$\mathrm{MeHg}$} & 28 & $6.2 \pm 0.9$ & $0.96 \pm 0.08$ & $0.29 \pm 0.16$ & $0.47 \pm 0.05$ & $0.38 \pm 0.07$ & $2.6 \pm 0.1$ \\
\hline & 56 & $6.3 \pm 1.4$ & $0.5 \pm 0.2$ & $0.59 \pm 0.21$ & $0.5 \pm 0.1$ & $1.6 \pm 1.0$ & $3.3 \pm 1.1$ \\
\hline \multirow{2}{*}{ Fish } & 28 & $5.1 \pm 0.7$ & $0.5 \pm 0.2$ & $0.18 \pm 0.05$ & $0.44 \pm 0.05$ & $0.23 \pm 0.06$ & $2.5 \pm 0.2$ \\
\hline & 56 & $3.4 \pm 1.7$ & $0.6 \pm 0.3$ & ${ }^{\circ \circ} 0.61 \pm 0.03$ & $0.3 \pm 0.1$ & $0.16 \pm 0.09$ & $1.7 \pm 0.9$ \\
\hline \multicolumn{8}{|l|}{ Midbrain } \\
\hline Control & 28 & $13.8 \pm 2.8$ & $6.8 \pm 1.8$ & $2.0 \pm 0.8$ & $3.3 \pm 1.3$ & $3.7 \pm 0.8$ & $22 \pm 5$ \\
\hline Control & 56 & $17.0 \pm 2.9$ & $9.0 \pm 1.4$ & $2.1 \pm 0.2$ & $3.5 \pm 0.5$ & $9.5 \pm 2.2$ & $23 \pm 4$ \\
\hline $\mathrm{MeHg}$ & 28 & $14.1 \pm 2.5$ & $8.6 \pm 1.0$ & $2.2 \pm 0.4$ & $3.7 \pm 0.8$ & $5.6 \pm 1.2$ & $19 \pm 3$ \\
\hline & 56 & $11.8 \pm 7.3$ & $4.0 \pm 1.1$ & $2.5 \pm 0.4$ & $3.1 \pm 0.4$ & $7.8 \pm 5.6$ & $14.5 \pm 0.9$ \\
\hline
\end{tabular}


Table 5: Continued.

\begin{tabular}{cccccccc}
\hline \multirow{2}{*}{ Brain structures and diets } & \multirow{2}{*}{ Days } & \multicolumn{5}{c}{ Neurotransmitters and decay products (pg/mg, mean \pm SEM, $n=3)$} \\
& & NE & DA & DOPAC & HVA & 5-HT & 5-HIAA \\
\hline \multirow{2}{*}{ Fish } & 28 & $13.1 \pm 1.4$ & $7.1 \pm 1.2$ & $1.7 \pm 0.6$ & $3.2 \pm 1.2$ & $5.7 \pm 1.0$ & $17 \pm 4$ \\
& 56 & $10.0 \pm 1.3$ & $5.8 \pm 1.1$ & $1.8 \pm 0.1$ & $3.29 \pm 0.05$ & $2.8 \pm 1.3$ & $16 \pm 1$ \\
\hline
\end{tabular}

${ }^{\mathrm{a}} \mathrm{MeHg}$ : mice were fed a MeHg-containing diet.

bish: mice were fed a $4.9 \%$ aimara flesh-containing diet.

NE: noradrenalin, DA: dopamine, DOPAC: 3,4-dihydroxyphenylacetic acid, HVA: homovanillic acid, 5-HT: 5-hydroxytryptamine or serotonin, 5-HIAA: 5hydroxyindole-acetic acid.

Values appearing in bold characters highlight those significantly different from the control values.

Asterisks indicate significant differences in the levels of neurotransmitters or decay products in the brain structures of mice fed the MeHg-containing diet compared to those fed the control diet, as determined with the Students test, $* P<0.05$.

Circles indicate significant differences in the levels of neurotransmitters or decay products in the brain structures of mice fed the fish-containing diet compared to those fed the control diet, as determined with the Students test, ${ }^{\circ} P<0.05$, and ${ }^{\circ \circ} P<0.01$.

The symbol $\S$ indicates significant differences in the levels of neurotransmitters or decay products in the brain structures of mice fed the fish-containing diet compared to those fed the MeHg-containing diet, as determined with the Students test, ${ }^{\S} P<0.05$.

cognitive performance of the mice fed the fish diet after 2 months of exposure.

\section{Conclusion}

The two mercury-containing diets are differing by the fact that mercury was brought by the addition of either pure methylmercury chloride or by mercurial species associated to fish. Therefore, any differential effects observed between $\mathrm{MeHg}$-containing and fish-containing diets should be attributed to different chemical species of mercury present in one diet and absent from the other and viceversa along with the possible intervening role of fish PUFA and selenium. If the beneficial role of fish nutriments such as PUFA and selenium was to counteract $\mathrm{MeHg}$ effects, the pattern of effects displayed after exposure to the fish-containing diet should appear less severe than that observed with the $\mathrm{MeHg}$-containing diet. But in the present study, the mice fed the fish-containing diet displayed worse behavioral performances than those fed the control and the $\mathrm{MeHg}$-containing diets, although the brain structures of both mercury-contaminated groups of mice contained comparable levels of mercury and even less in the striatum of those fed the fish diet. Therefore, the different chemical species of mercury within fish flesh are likely to explain the deficit in cognitive performance in the $\mathrm{Y}$ maze and the decreased locomotory activity in the open-field maze.

\section{Acknowledgments}

The authors thank Ayumi Onitsuka for their technical help and the Agence Nationale de la Recherche for its financial support (Grant no. 05 SEST 034 01).

\section{References}

[1] J. P. Bourdineaud, N. Bellance, G. Bénard et al., "Feeding mice with diets containing mercury-contaminated fish flesh from French Guiana: a model for the mercurial intoxication of the Wayana Amerindians," Environmental Health, vol. 7, article 53, 2008.
[2] J. P. Bourdineaud, M. Fujimura, M. Laclau, M. Sawada, and A. Yasutake, "Deleterious effects in mice of fish-associated methylmercury contained in a diet mimicking the Western populations' average fish consumption," Environment International, vol. 37, no. 2, pp. 303-313, 2011.

[3] M. H. G. Berntssen, K. Hylland, A. K. Lundebye, and K. Julshamn, "Higher faecal excretion and lower tissue accumulation of mercury in Wistar rats from contaminated fish than from methylmercury chloride added to fish," Food and Chemical Toxicology, vol. 42, no. 8, pp. 1359-1366, 2004.

[4] G. N. George, S. P. Singh, R. C. Prince, and I. J. Pickering, "Chemical forms of mercury and selenium in fish following digestion with simulated gastric fluid," Chemical Research in Toxicology, vol. 21, no. 11, pp. 2106-2110, 2008.

[5] H. H. Harris, I. J. Pickering, and G. N. George, "The chemical form of mercury in fish," Science, vol. 301, no. 5637, p. 1203, 2003.

[6] Y. Oyama, Y. Yamazaki, Y. Okada, K. Takahama, M. Satoh, and H. Hayashi, "Toxicity of methylmercury conjugated with Lcysteine on rat thymocytes and human leukemia K562 cells in comparison with that of methylmercury chloride," Environmental Toxicology and Pharmacology, vol. 9, no. 1-2, pp. 49-55, 2000.

[7] H. E. Ganther, C. Goudie, M. L. Sunde, M. J. Kopecky, and P. Wagner, "Selenium: relation to decreased toxicity of methylmercury added to diets containing tuna," Science, vol. 175, no. 4026, pp. 1122-1124, 1972.

[8] H. E. Ganther, "Modification of methylmercury toxicity and metabolism by selenium and vitamin E: possible mechanisms," Environmental Health Perspectives, vol. 25, pp. 71-76, 1978.

[9] C. J. Passos, D. Mergler, E. Gaspar et al., "Eating tropical fruit reduces mercury exposure from fish consumption in the Brazilian Amazon," Environmental Research, vol. 93, no. 2, pp. 123-130, 2003.

[10] R. Canuel, S. B. de Grosbois, M. Lucotte, L. Atikessé, C. Larose, and I. Rheault, "New evidence on the effects of tea on mercury metabolism in humans," Archives of Environmental and Occupational Health, vol. 61, no. 5, pp. 232-238, 2006.

[11] X. Jin, E. Lok, G. Bondy et al., "Modulating effects of dietary fats on methylmercury toxicity and distribution in rats," Toxicology, vol. 230, no. 1, pp. 22-44, 2007.

[12] M. J. McVey, G. M. Cooke, I. H. A. Curran et al., "An investigation of the effects of methylmercury in rats fed different dietary fats and proteins: testicular steroidogenic enzymes and 
serum testosterone levels," Food and Chemical Toxicology, vol. 46, no. 1, pp. 270-279, 2008.

[13] A. Boudou, R. Maury-Brachet, M. Coquery, G. Durrieu, and D. Cossa, "Synergic effect of gold mining and damming on mercury contamination in fish," Environmental Science and Technology, vol. 39, no. 8, pp. 2448-2454, 2005.

[14] M. Tanaka, R. Ohtani-Kaneko, M. Yokosuka, and C. Watanabe, "Low-dose perinatal diethylstilbestrol exposure affected behaviors and hypothalamic estrogen receptor- $\alpha$-positive cells in the mouse," Neurotoxicology and Teratology, vol. 26, no. 2, pp. 261-269, 2004.

[15] J. Podhorna and R. E. Brown, "Strain differences in activity and emotionality do not account for differences in learning and memory performance between C57BL/6 and DBA/2 mice," Genes, Brain and Behavior, vol. 1, no. 2, pp. 96-110, 2002.

[16] A. Yasutake, M. Nagano, and A. Nakano, "Simple method for methylmercury estimation in biological samples using atomic absorption spectroscopy," Journal of Health Science, vol. 51, no. 2, pp. 220-223, 2005.

[17] T. A. Simmons-Willis, A. S. Koh, T. W. Clarkson, and N. Ballatori, "Transport of a neurotoxicant by molecular mimicry: the methylmercury-L-cysteine complex is a substrate for human L-type large neutral amino acid transporter (LAT) 1 and LAT2," Biochemical Journal, vol. 367, no. 1, pp. 239-246, 2002.

[18] L. E. Kerper, N. Ballatori, and T. W. Clarkson, "Methylmercury transport across the blood-brain barrier by an amino acid carrier," American Journal of Physiology, vol. 262, no. 5, pp. R761-R765, 1992.

[19] N. Ballatori, "Transport of toxic metals by molecular mimicry," Environmental Health Perspectives, vol. 110, no. 5, pp. 689694, 2002.

[20] J. J. Leaner and R. P. Mason, "Methylmercury accumulation and fluxes across the intestine of channel catfish, Ictalurus punctatus," Comparative Biochemistry and Physiology C, vol. 132, no. 2, pp. 247-259, 2002.

[21] D. Grotto, J. Valentini, J. M. Serpeloni et al., "Evaluation of toxic effects of a diet containing fish contaminated with methylmercury in rats mimicking the exposure in the Amazon riverside population," Environmental Research, vol. 111, no. 8, pp. 1074-1082, 2011.

[22] L. R. F. Faro, R. Durán, J. L. M. do Nascimento, M. Alfonso, and C. W. Picanço-Diniz, "Effects of methyl mercury on the in vivo release of dopamine and its acidic metabolites DOPAC and HVA from striatum of rats," Ecotoxicology and Environmental Safety, vol. 38, no. 2, pp. 95-98, 1997.

[23] H. Takahashi, M. Kato, H. Takano et al., "Differential contributions of prefrontal and hippocampal dopamine D 1 and D2 receptors in human cognitive functions," The Journal of Neuroscience, vol. 28, no. 46, pp. 12032-12038, 2008. 

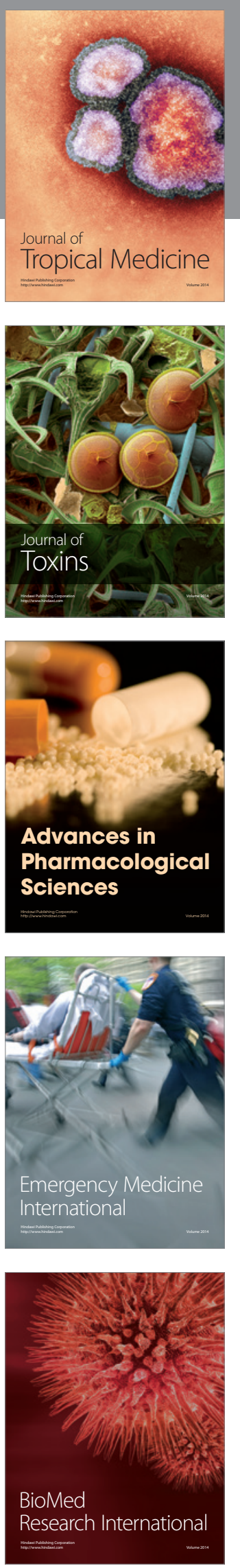
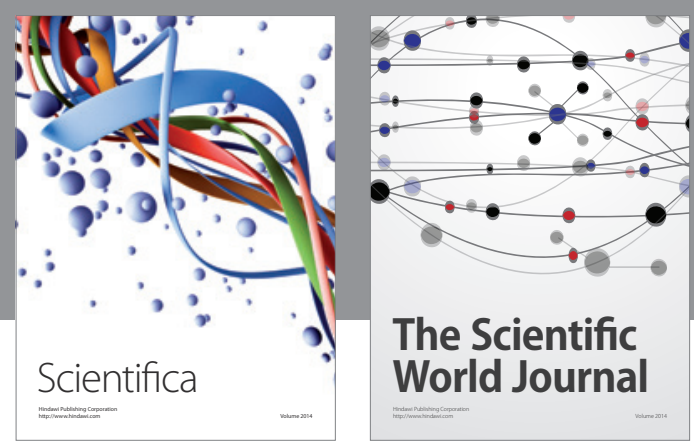

The Scientific World Journal
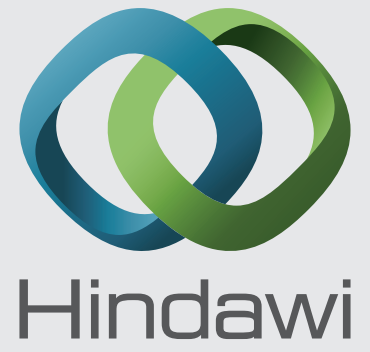

Submit your manuscripts at

http://www.hindawi.com
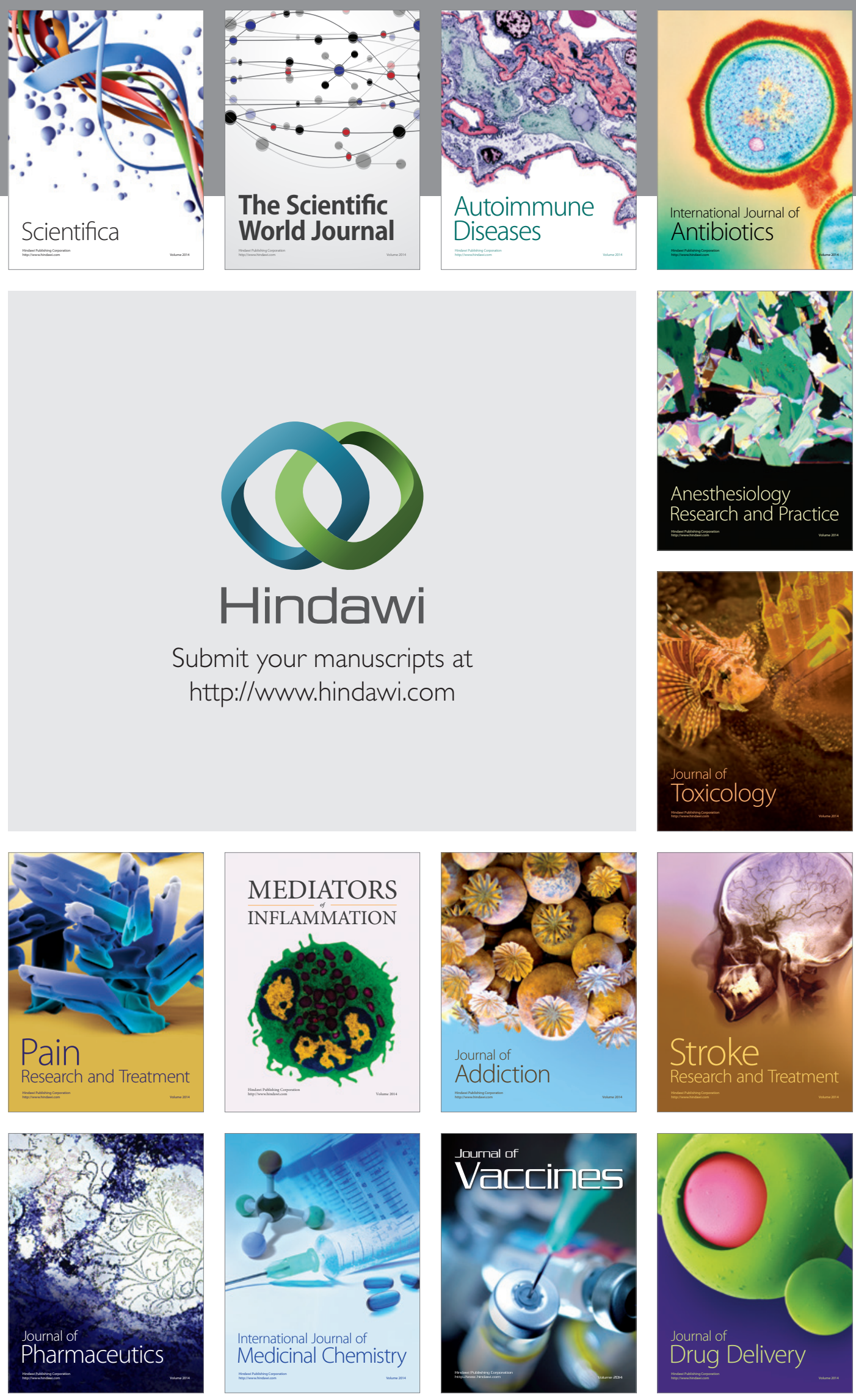